Research Paper

\title{
Perancangan dan Analisis Ekonomi Pembangunan Pembangkit Listrik Tenaga Piko Hidro di Desa Garabak Data Kabupaten Solok Sumatera Barat
}

\author{
Adly Havendri ${ }^{1}$, Dendi Adi Saputra ${ }^{1}$, Mulya Cipta Nurmansyah ${ }^{2}$ \\ ${ }^{I}$ Dosen Jurusan Teknik Mesin, Universitas Andalas, Padang, Indonesia \\ ${ }^{2}$ Mahasiswa Program Sarjana Jurusan Teknik Mesin Universitas Andalas, Padang, Indonesia
}

\section{INFORMASI ARTIKEL}

\section{Sejarah Artikel:}

Diterima Redaksi: 03 Februari 2017

Revisi Akhir: 01 Maret 2017

Diterbitkan Online: 01 April 2017

\section{KATA KUNCI}

Pico hydro

Power

Electric

Turbine

Generator

\begin{abstract}
A B S T R A C T
In this research, development of a pico hydro power plant utilizing the river with water flow $0.6 \mathrm{~m}^{3} / \mathrm{s}$ and head $1.5 \mathrm{~m}$ is conducted. According to the available potential of the area, the waterwheel turbine with type undershot and efficiency about $71-76 \%$ is selected. The synchronize generator with 1 phase and $10 \mathrm{kVA}$ capacity is chosen according the maximum generated power of the plant power which is about $8.81 \mathrm{~kW}$. Due to the loses inside the turbine and generator, therefore the average electrical power that can be distributed is 4.96 $\mathrm{kW}$. For stabilizing the voltage and current from the generator, a 7,5 kVA stabilizer with safety factor $20 \%$ is used. As the result, the stable electrical power $34.759,68 \mathrm{kWh}$ can be generated every year with the capacity factor about $80 \%$. The design results of the pico hydro power plant indicated that the power plant in Garabak Data able to produce the electrical power about Rp899,05 per kWh.
\end{abstract}

KORESPONDENS

E-mail: adlyhave05@gmail.com

\section{PENDAHULUAN}

Berdasarkan data Direktorat Jendral Listrik dan Pemanfaatan Energi (DJLPE) pada tahun 2008 Indonesia merupakan salah satu negara yang memiliki potensi air yang besar karna memiliki begitu banyak aliran sungai dan danau yang dapat dimanfaatkan menjadi sumber energi yaitu dari sekitar 75.67 GW energi yang ada, baru dimanfaatkan sekitar 4.2 GW. Diantara potensi tersebut digunakan untuk pembangkit listrik tenaga piko hidro sekitar 450 MW dan yang baru dimanfaatkan sekitar 230 MW. Pencapaian rasio elektrifikasi baru mencapai $64 \%$ dan rasio desa yang mendapatkan energi listrik mencapai $88 \%$ dari total 66.000 desa [1, 2]. Garabak Data adalah sebuah desa di Kecamatan Tigo Lurah, Kabupaten Solok, Sumatera Barat yang masih mendapatkan energi listrik sampai saat ini. Ditinjau dari lokasinya, Desa Garabak Data memiliki potensi pemanfaatan aliran sungai sebagai sumber energi pembangkit listrik tenaga piko hidro. Hal ini dapat dilihat dari karakteristik aliran sungai yang memiliki head rendah namun debit yang tinggi. Selain itu, lokasi aliran sungai yang terdapat di sekitar permukiman penduduk akan memudahkan 


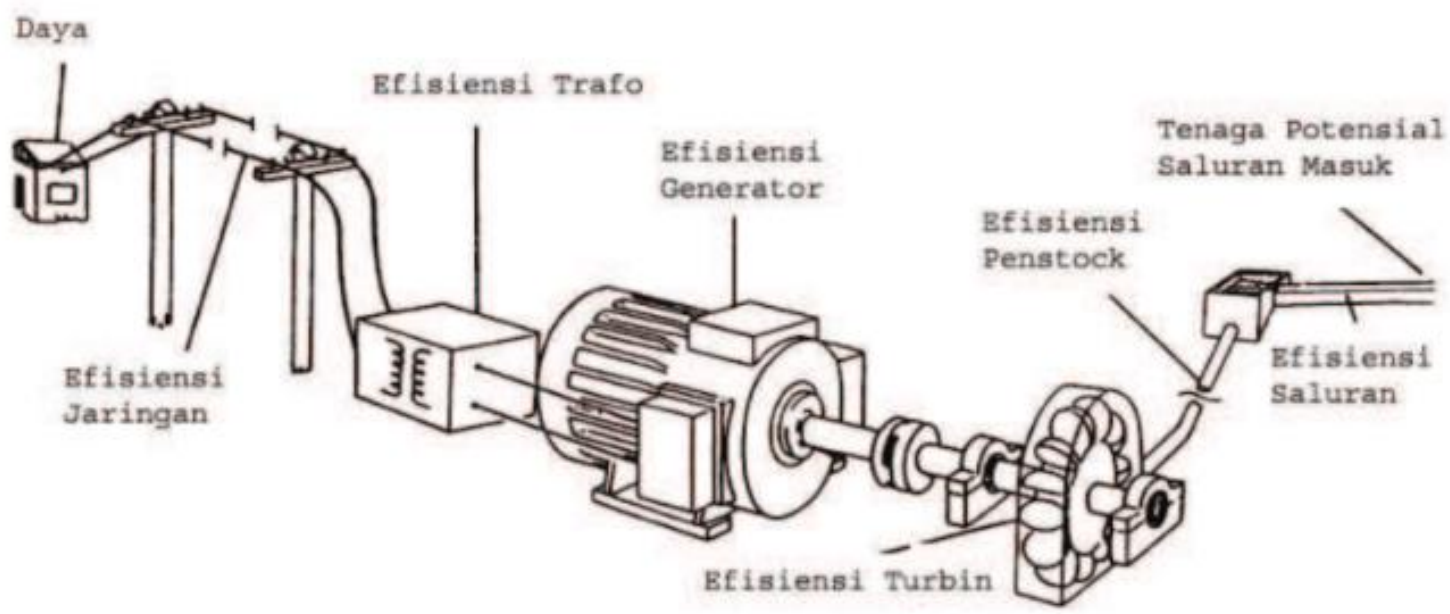

Gambar 1. Skema pembangkit listrik piko hidro

akses dalam perancangan dan pembangunan PLTPH ini nantinya. Oleh sebab itu, diperlukan sebuah kajian awal mengenai peraancangan dan analisis ekonomi untuk melihat kelayakan pembangunan PLTPH ini.

\section{KAJIAN PUSTAKA}

Sistem pembangkit tenaga listrik membutuhkan sumber-sumber energi dari alam untuk mengubah suatu energi menjadi energi lain, dan yang dikaji pada penelitian kali ini yaitu energi listrik yang diperoleh berdasarkan hukum kekekalan energi (hukum termodinamika 1) yaitu: energi tidak bisa diciptakan ataupun dimusnahkan, namun dapat berubah dari satu bentuk ke bentuk yang lain [3]. Pada umumnya untuk membangkitkan energi listrik dibutuhkan energi mekanik berupa kecepatan dan putaran pada poros untuk memutar poros generator sehingga menghasilkan energi listrik. Sumber energi mekanik itu bisa didapat dari tenaga air, tenaga angin, tenaga uap, tenaga geothermal, tenaga gas, tenaga diesel, tenaga nuklir. Pada Gambar 1 diperlihatkan skema pembangkit energi listrik piko hidro. Pada Gambar 1 tersebut terlihat bahwa energi potensial air disimpan pada tempat penyimpanan sementara yang berada di ketinggian tertentu. Air ini selanjutnya dialirkan ke dalam turbin yang digunakan untuk menggerakkan generator.
Daya listrik yang dihasilkan oleh generator pembangkit listrik piko hidro berasal dari energi potensial air pada ketinggian $h$ dan dikurangi oleh rugi-rugi energi pada turbin dan generator [4].

$P=\rho \times g \times Q \times h \times \eta_{\text {turbin }} \times \eta_{\text {generator }}$

\subsection{Kriteria Pemilihan Jenis Bahan}

Parameter-parameter khusus yang mempengaruhi sistem operasi turbin, yaitu:

1. Faktor tinggi jatuhan air efektif ( $\mathrm{Net} \mathrm{Head)} \mathrm{dan}$ debit yang akan dimanfaatkan untuk operasi turbin merupakan faktor utama yang mempengaruhi pemilihan jenis turbin.

2. Faktor daya (power) yang diinginkan berkaitan dengan head dan debit yang tersedia.

3. Kecepatan (putaran) turbin yang akan ditransmisikan ke generator.

\subsection{Skema Sipil Pembangunan PLTPH}

Pada suatu lokasi yang berpotensi untuk membangkitkan energi piko hidro dapat dipetakan sebagai suatu sistem yang terdiri dari komponenkomponen bangunan sipil seperti bendungan, bangunan pengambil, saluran pembawa, bak pengendap, saluran pelimpah, pipa pesat, rumah pembangkit dan saluran buang [5]. Pada Gambar 2 diperlihatkan peta dari suatu sistem pembangkit listrik piko hidro. 


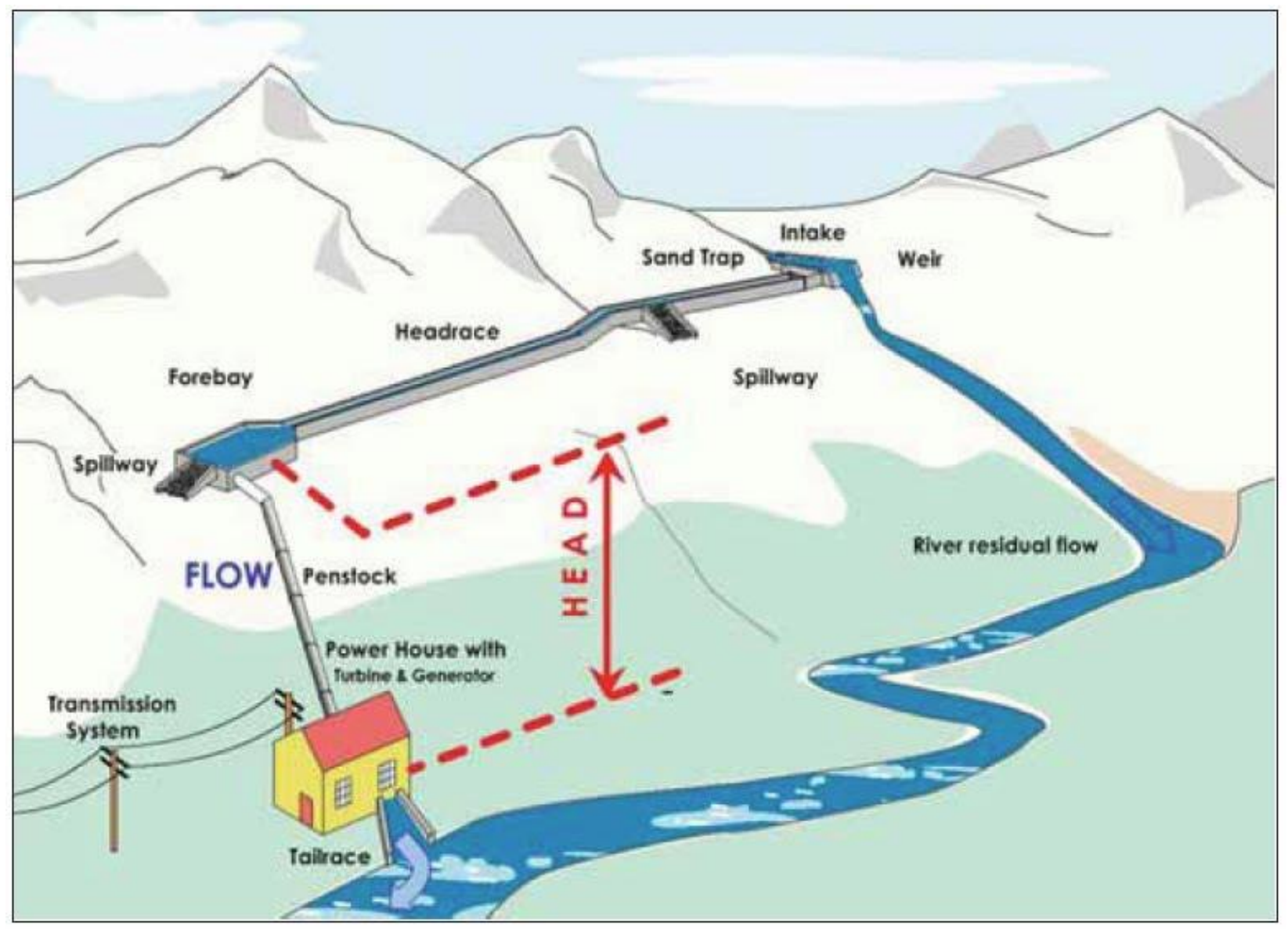

Gambar 1. Skema pembangkit listrik piko hidro

\section{METODOLOGI}

Secara garis besar, tahapan penelitian diperlihatkan dalam bentuk diagram alair pada Gambar 3 . Tahapan-tahapan penelitian tersebut adalah:

a. Studi Literatur

Studi Literatur yang dilakukan adalah memperlajari dan memahami konsep mengenai perancangan PLTPH, yang mencakup studi kelayakan pendirian suatau pembangkit dan analisis ekonomi. Selain itu dilakukan megenai metode pengkurukan head dan debit aliran air dari sungai di daerah Garabak Data.

b. Survei Lapangan

Survei lapangan dilakukan untuk mengetahui potensi aliran sungai untuk dimanfaatkan sebagai lokasi intake pembangkit sertla melakukan pengukuran head dan debit aliran sungai.

c. Perancangan PLTPH

Perancangan PLTPH meliputi konstruksi komponen sipil dan peralatan mekanikal elektrikal yang optimal dari sistem suatu pembangkit, serta mengkalkulasikan rancangan anggaran biaya.

d. Analisis Ekonomi Teknik

Analisis ekonomi teknik dilakukan untuk mengetahui layak atau tidaknya pembangunan suatu pembangkit sesuai standar literatur yang telah ditetapkan.

e. Penarikan Kesimpulan

Hasil dari kesimpulan adalah perancangan pembangunan PLTPH di Desa Garabak Data layak untuk dijalankan. 


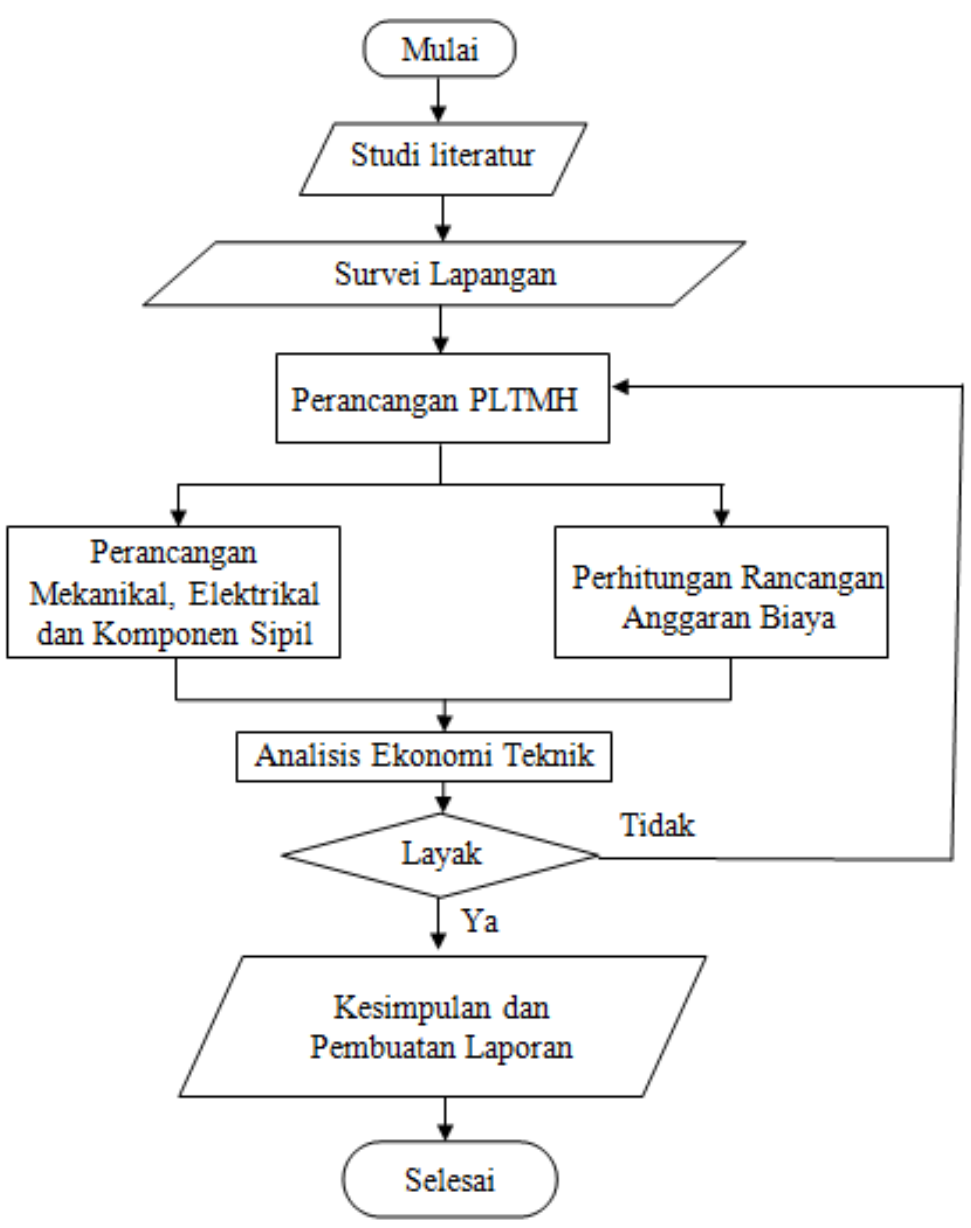

Gambar 3. Diagram alir penelitian

\section{HASIL DAN PEMBAHASAN}

\subsection{Data Potensi}

Berdasarkan hasil survei di desa Garabak Data, lokasi ini berpotensi untuk dibangunnya pembangkit listrik tenaga piko hidro. Survei lapangan telah dilakukan untuk mengetahui kondisi data sungai sebagai berikut. Tabel 1 memperlihatkan hasil dari pengukuran data di sungai. Hasil pengukuran menunjukkan bahwa lebar sungai adalah $4 \mathrm{~m}$ dengan kedalaman rata-rata 0,496 m sehingga luas penampang sungai adalah $1,984 \mathrm{~m}^{2}$. Selanjuntya dilakukan pengukuran kecepatan aliran dengan panjang aliran diukur $10 \mathrm{~m}$ dengan waktu rata-rata yang diapatkan adalah 19,98 s, sehingga diperoleh kecepatan aliran yaitu 0,5004

$\mathrm{m} / \mathrm{s}$. Untuk mendapatkan debit air dihitung sebagai berikut:

$Q=A \times v$

$Q=1,984 \mathrm{~m}^{2} \times 0,5004 \mathrm{~m} / \mathrm{s}$

$Q=0,992 \mathrm{~m}^{3} / \mathrm{s}$

Dengan menggunakan data-data hasil pengukuran serta hasil perhitungan debit maka untuk perancangan turbin piko hidro digunakan parameter sebagai berikut:

- Head

- Debit Air

- Massa Jenis Air

- Percepatan Gravitasi
$: 1,5 \mathrm{~m}$

: $0,992 \mathrm{~m}^{3} / \mathrm{s}$

: $998 \mathrm{~kg} / \mathrm{m}^{3}$

: $9,81 \mathrm{~m} / \mathrm{s}^{2}$ 
Tabel 1. Data hasil pengukuran di sungai

\begin{tabular}{|c|c|c|c|c|c|c|c|c|}
\hline No & Uraian & Satuan & \multicolumn{5}{|c|}{ Nomor Pengukuran } & \multirow[t]{5}{*}{ Keterangan } \\
\hline \multirow[t]{7}{*}{1} & \multirow{4}{*}{$\begin{array}{l}\text { Waktu } \\
\text { Pengukuran }\end{array}$} & \multirow{4}{*}{ s } & 1 & 2 & 3 & 4 & 5 & \\
\hline & & & 19,54 & 19,66 & 19,85 & 19,56 & 19,83 & \\
\hline & & & 6 & 7 & 8 & 9 & 10 & \\
\hline & & & 20,52 & 21,27 & 19,52 & 19,93 & 20,18 & \\
\hline & \begin{tabular}{|l|l|} 
Panjang \\
Lintasan \\
\end{tabular} & $\mathrm{m}$ & \multicolumn{5}{|c|}{10} & \multirow{10}{*}{$\begin{array}{l}\mathrm{L}=4 \mathrm{~m} \\
\mathrm{~W}=0,4 \mathrm{~m}\end{array}$} \\
\hline & $\begin{array}{l}\begin{array}{l}\text { Waktu rata- } \\
\text { rata }\end{array} \\
\end{array}$ & s & \multicolumn{5}{|c|}{19,986} & \\
\hline & $\begin{array}{l}\text { Kecepatan } \\
\text { Aliran }\end{array}$ & $\mathrm{m} / \mathrm{s}$ & & \multicolumn{3}{|c|}{0,5004} & \\
\hline \multirow[t]{6}{*}{2} & \multirow{4}{*}{$\begin{array}{l}\text { Kedalaman } \\
\text { (d) }\end{array}$} & \multirow{4}{*}{$\mathrm{m}$} & 1 & 2 & 3 & 4 & 5 & \\
\hline & & & 0,15 & 0,28 & 0,61 & 0,72 & 0,86 & \\
\hline & & & 6 & 7 & 8 & 9 & 10 & \\
\hline & & & 0,69 & 0,67 & 0,48 & 0,38 & 0,12 & \\
\hline & \begin{tabular}{|l|}
$\begin{array}{l}\text { Kedalaman } \\
\text { rata-rata }\end{array}$ \\
\end{tabular} & $\mathrm{m}$ & \multicolumn{5}{|c|}{0,496} & \\
\hline & \begin{tabular}{|l|} 
Luas \\
Penampang
\end{tabular} & $\mathrm{m}^{2}$ & \multicolumn{5}{|c|}{1,984} & \\
\hline 3 & Debit Air & $\mathrm{m}^{3 / \mathrm{s}}$ & \multicolumn{5}{|c|}{0,9926} & \\
\hline
\end{tabular}

\subsection{Peralatan Mekanikal Elektrikal}

\subsubsection{Pemilihan Turbin}

Pemilihan jenis turbin dipilih berdasarkan pada tinggi air jatuh (head) dan debit aliran yang mengalir. Berdasarkan hasil survei dan analisa dalam perancangan, head yang dirancang yaitu 1,5 $\mathrm{m}$ dengan debit $0,6 \mathrm{~m}^{3} / \mathrm{s}$. Berdasarkan data head dan debit yang didapatkan maka jenis turbin terbaik yang dipilih adalah jenis water wheel tipe undershoot karena jenis ini dapat digunakan pada head yang sangat kecil yaitu antara 1,2 - 2,3 m dengan debit aliran sampai dengan $3 \mathrm{~m}^{3} / \mathrm{s}$, namun efisiensi jenis turbin water wheel undershot ini paling kecil diatara jenis water wheel lainnya yaitu sebesar 71-76\% [6,7]. Setelah didapatkan jenis turbin yang sesuai, dilakukan perancangan berdasarkan strandar yang merujuk pada standar perancangan turbin. Geometri perancangan dari turbin kincir air undershot adalah sebagai berikut:

- Diameter luar turbin $\quad: 1 \mathrm{~m}$

- Diameter dalam turbin $\quad: 0,75 \mathrm{~m}$

- Tebal rotor

$: 8 \mathrm{~mm}$

- Tebal sudu

$: 6 \mathrm{~mm}$

- Luas Sudu

: $0,0626 \mathrm{~m}^{2}$

- Jumlah Sudu

: 3 buah

- Diameter Poros

$: 10 \mathrm{~cm}$

- Kecepatan putar

: $50 \mathrm{rpm}$

\subsubsection{Pemilihan Generator}

Terdapat dua jenis generator yaitu generator sinkron dan generator induksi. Generator yang dipilih yaitu generator sinkron dengan alasan lebih mudah dioperasikan dan lebih mudah ditemukan dipasaran. Inti lilitan dinamo terbuat dari material tembaga. Pemilihan lilitan tembaga dipilihan karna memiliki efisiensi daya hantar listrik yang tinggi. Spesifikasi Generator yang akan digunakan adalah:

- Daya : $10 \mathrm{kVA}$

- Tipe : 1 phasa

- Volt :230 V

- Arus :21,8 A

- Frekuensi : $50 \mathrm{~Hz}$

- Putaran : $1500 \mathrm{rpm}$

\subsubsection{Sistem Penyaluran Tenaga Listrik}

Tegangan serta arus listrik keluran generator tidak selalu stabil, untuk menjaganya tetap stabil diperlukan stablizer pada instalasi listrik. Stabilizer listrik memiliki harga maksimum daya output yang berbeda-beda. Stabilizer sebaiknya tidak digunakan sampai beban $100 \%$ agar stablizier tahan lama. Faktor keamanan diperlukan untuk menjaga performa stabilizer. Perancangan stabilizer mengunakan daya maksimum $80 \%$ dan faktor keamanan $20 \%$.

- Power Maksimum : 80\%

- Arus listrik $: 21,8 \mathrm{~A}$

- Tegangan Listrik :230 V

- Faktor keamanan : $20 \%$

Daya stabilizer dihitung sebagai berikut:

$$
\begin{aligned}
P_{\text {stabilizer }}= & \begin{array}{c}
\text { Tegangan } \times \text { Arus } \\
\text { Power Maksimum } \\
\times \text { Faktor Keamanan }
\end{array} \\
P_{\text {stabilizer }}= & \frac{230 \mathrm{~V} \times 21,8 \mathrm{~A}}{80 \%} \times 20 \% \\
P_{\text {stabilizer }}= & 7521 \mathrm{VA}
\end{aligned}
$$

Sesuai dengan hasil perhitungan maka stabilizer yang tepat digunakan yaitu minimal 7500 VA. Setelah melewati stabilizer daya telah stabil maka listrik dapat didistribusikan sehingga tidak merusak 
peralatan eletrik konsumen karena ketidakstabilan voltase.

\subsection{Skema dan Komponen Sipil}

1. Intake

Pada umumnya sebelum menentukan lokasi intake ada beberapa hal yang harus diperhatikan salah satunya yaitu kondisi dasar sungai yang stabil sehingga tidak mudah terjadinya erosi yang mengakibatkan sulitnya air memasuki intake.

2. Bak Penenang (Headtank)

Bak penenang dirancang dengan volume $3 \mathrm{~m} \mathrm{x}$ $3 \mathrm{~m} \times 1.5 \mathrm{~m}$, untuk mendapatkan debit yang konstan sebesar $0.6 \mathrm{~m}^{3} / \mathrm{s}$ diameter orifice yang digunakan yaitu $40 \mathrm{~cm}$ di dasar bak penenang.

3. Penstock

Penstock berfungsi mengalirakan air dari bak penenang menuju turbin dengan panjang rancangan 17,2 $\mathrm{m}$ dengan kemiringan $5^{\circ}$ dan langsung menumbuk sudu turbin dengan net head $1,5 \mathrm{~m}$.

\subsection{Perhitungan Daya Terbangkit}

Dengan menggunakan persamaan 1 dapat diprediksi daya air yang tersedia untuk turbin dengan efisiensi mekanik sebesar $75 \%$ dan efisiensi generator $75 \%$ maka kapasitas daya terbangkit dengan debit rancangan $0.6 \mathrm{~m}^{3 /} \mathrm{s}$ yaitu:

$P_{w}=\rho \times g \times Q \times h \times \eta_{\text {turbin }} \times \eta_{\text {generator }}$

$P_{w}=998 \frac{\mathrm{kg}}{\mathrm{m}^{3}} \times 9,81 \frac{\mathrm{m}}{\mathrm{s}^{2}} \times 0,6 \mathrm{~m}^{3} / \mathrm{s} \times 1,5 \mathrm{~m}$

$$
\times 0,75 \times 0,75
$$

$P_{w}=4956,4$ watt

Jika satu rumah mendapatkan batas pemakaian listrik $220 \mathrm{kVA}$, maka dengan kapasitas daya terbangkit oleh PLTPH dapat didistribusikan listrik ke 22 rumah yang ada di desa Garabak Data.

\subsection{Analisis Biaya}

\subsubsection{Performa Cash Flow}

Penyusutan performa cash flow menggunakan asumsi:
1. Tingkat inflasi
$=3,5 \%$
2. Suku bunga
$=10,75 \%$
3. Kenaikan tarif listrik/tahun $=15 \%$
4. Pajak
$=3 \%$
5. Umur Ekonomis Pembangkit $=20$ Tahun

\subsubsection{Investasi Awal}

Investasi awal merupakan seluruh biaya yang harus dikeluarkan untuk pembangunan dari tahap persiapan sampai tahap pembangkit dapat mendistribusikan energi listrik ke konsumen. Estimasi investasi awal pendirian pembangkit yaitu sebesar Rp 61.270.000.

\subsubsection{Biaya Operasional}

Biaya operasional merupakan biaya tahunan yang dikeluarkan setiap tahun untuk perawatan PLTPH, gaji operator dan keperluan lain. Kebutuhan biaya operasional yaitu sebesar Rp 36.000.000.

\subsubsection{Penerimaan dari PLTPH}

Prediksi daya listrik yang dihasilkan oleh pembangkit per tahun dengan kapasitas faktor $80 \%$

$$
\begin{aligned}
\mathrm{P} & =4,96 \mathrm{~kW} \times 365 \text { hari } \mathrm{x} 24 \mathrm{~h} \times 80 \% \\
& =34.759,68 \mathrm{kWh}
\end{aligned}
$$

Berdasarkan peraturan Menteri Energi dan Sumber Daya Mineral Republik Indonesia Nomor 19 Tahun 2015 tentang pembelian tenaga listrik dari pembangkit listrik tenaga air dengan kapasitas sampai dengan $10 \mathrm{MW}$ di daerah Sumatera untuk tegangan rendah oleh PT. Perusahaan Listrik Negara bahwa harga pembelian tenaga listrik dari PLTA yang memanfaatkan tenaga air dari waduk/ bendungan atau saluran irigasi yang pembangunannya bersifat multiguna dengan kapasitas sampai dengan 10 MW berdasarkan hasil berikut dengan harga satu US Dollar terhadap Rupiah adalah Rp 13.226,50 [8]. 


\subsection{Harga Daya Terbangkit PLTPH}

Hasil perancangan PLTPH dengan kapasitas daya terbangkit yaitu sebesar $4,96 \mathrm{~kW}$ membutuhkan biaya Rp 61.270.000 dengan umur ekonomis pembangkit selama 20 tahun membutuhkan biaya operasional $\mathrm{Rp} 36.000 .000$ per tahun, maka ratarata biaya per hari adalah:

$R p /$ hari $=\frac{\text { Biaya awal }+ \text { Biaya operasional }}{\text { Umur ekonomis } \times 365 \text { hari }}$

$R p /$ hari $=\frac{R p 61.270 .000+R p 720.000 .000}{20 \text { tahun } \times 365 \text { hari }}$

$R p /$ hari $=\operatorname{Rp} 107.023,28$

Biaya per kWh ditentukan dari biaya listrik per hari dan besarnya energi listrik yang dikonsumsi, maka harga daya terbangkit yang didapatkan yaitu sebesar:

Biaya $/ k W h=\frac{\text { Biaya per hari }}{\text { Energi Listrik }(k W h / \text { hari })}$

Biaya $/ k W h=\frac{R p 107.023,28}{4,96 k W h \times 24 \text { jam } / \text { hari }}$

Biaya $/ k W h=\operatorname{Rp} 899,05$

\section{KESIMPULAN DAN SARAN}

\subsection{Kesimpulan}

1. Hasil perancangan PLTPH di desa Garabak Data menghasilkan daya total sebesar 4,96 kW dengan daya terbangkit per tahun 34.759,68 kWh dengan faktor kapasitas $80 \%$.

2. Berdasarkan potensi head $1,5 \mathrm{~m}$ dan debit 0,6 $\mathrm{m}^{3} / \mathrm{s}$ maka turbin yang paling efektif yaitu tipe waterwheel undershot.

3. Harga daya terbangkit yang dihasilkan sebesar Rp 899,05 per kWh.

\subsection{Saran}

Daya yang terbangkit dari pembangkit listrik piko hidro tergolong kecil untuk itu pendistribusian energi listrik ke konsumen tidak boleh melebihi beban yang diizinkan.

\section{DAFTAR PUSTAKA}

[1] Direktorat Jendral Listrik dan Pemanfaatan Energi. Pedoman Studi Kelayakan PLTPH. Jakarta: IMIDAP, 2009.

[2] Badan Pusat Statistik. "Kapasitas Terpasang, Tenaga Listrik yang Dibangkitkan, dan Listrik yang Didistribusikan Menurut Provinsi. Tersedia".

https://www.bps.go.id/linkTabelStatis/view/id/ $\underline{\text { 1858, }} 2014$ [5 Maret 2016].

[3] W. C. Reynolds, H. C. Perkins. Termodinamika Teknik edisi kedua. Alih Bahasa oleh F. Harahao. Jakarta: Erlangga, 1996.

[4] F. M. White. Mekanika Fluida edisi kedua. Jakarta: Erlangga, 1998.

[5] Kontrol dan Proteksi Pembangkit Listrik Tenaga Piko hidro. Tersedia http://indonesien.ahk.de/fileadmin/ahk_indone sien. [5 Maret 2016].

[6] Direktorat Jendral Listrik dan Pemanfaatan Energi. Pedoman Studi Kelayakan PLTPH Mekanikal Elektrikal. Jakarta: IMIDAP, 2009.

[7] Zecohydropower. "Pelton Turbine". Tersedia https://www.zeco.it/zeco-turbines/peltonturbine/. 2012.

[8] NN1. "Makalah Pembangkit Listrik Tenaga Air". Tersedia https://www.academia.edu/6251469/MAKAL AH PLTA 2013 [19 Maret 2016]. 